\title{
Motivational climate of group exercise sessions in nursing homes
}

\author{
Alexia Charles ( $\nabla$ alexia.charles@uliege.be) \\ University of Liège https://orcid.org/0000-0003-0296-7349 \\ Fanny Buckinx \\ University of Liège \\ Alexandre Mouton \\ University of Liège \\ Jean-Yves Reginster \\ University of Liège \\ Olivier Bruyère \\ University of Liège
}

\section{Research}

Keywords: motivational climate, exercise group, physical activity, older people, institutionalization

Posted Date: March 9th, 2020

DOI: https://doi.org/10.21203/rs.3.rs-16339/v1

License: (c) (1) This work is licensed under a Creative Commons Attribution 4.0 International License. Read Full License

Version of Record: A version of this preprint was published at Archives of Public Health on May 12th, 2020. See the published version at https://doi.org/10.1186/s13690-020-00425-y. 


\section{Abstract}

\section{Background}

Motivational climate in exercise group environments would have an impact on adherence, effort and enjoyment. We examined the motivational climate among nursing home residents who were involved in group exercise sessions.

\section{Methods}

This cross-sectional study was conducted in 10 nursing homes of Liège area that offer group exercise sessions. Sociodemographic data (age, sex, body mass index), cognitive status (by the Mini Mental State Examination) and independence in activities of daily living (by the Katz Scale) were retrieved in the medical records. The "Abbreviated-Perceived Motivational Climate in Exercise Questionnaire" was translated into French and then administered face to face with a clinical researcher. This is composed of 6 ego-involving climate items (corresponding to rivalry, comparison and favoritism) and 6 task-involving climate items (corresponding to valorization, individual efforts, self-improvement and cooperation). Each item is ranged on a 5-point Likert scale ranging from 1 (not at all focused on ego or task) to 5 (totally focused on ego or task). Each subscale has a total score expressed as an average.

\section{Results}

A total of 102 subjects of exercise group sessions were included ( $84.3 \pm 7.7$ years and $83(81.4 \%)$ women). The mean score of task-involving and ego-evolving motivational climate was respectively 3.57 $(S D=0.67)$ and $1.52(S D=0.49)$, suggesting that the motivational climate was more focused on the taskinvolving climate than on ego-involving climate. Some items results were of particular interest: $55.9 \%$ of the respondents found that the instructor doesn't remark/reward when they try hard, $63.7 \%$ said that the instructor doesn't encourage mutual aid and $38.2 \%$ found that instructor doesn't encourage to do new exercises.

\section{Conclusions}

Participants tended to perceive motivational climate as more task-involving than ego-involving. The absence of individual positive feedback, new exercises and mutual aid were also highlighted.

\section{Background}

There is a growing body of literature that recognizes the importance of physical activity in older people. It has previously been observed that engagement in physical activity has a positive impact on functional abilities (1,2), mobility (3), cognitive status (Maki et al. 2012; Arrieta et al. 2018), quality of life (4,5), risk of falls $(6)$ and mortality $(7,8)$. In addition, the International Association of Gerontology and Geriatrics (IAGG) and the World Health Organization (WHO) have emphasized the importance of physical exercise in the quality of nursing home care (9). 
However, the level of physical activity of nursing home residents is generally low (10), and it seems important to motivate them to move more. Therefore, special consideration should be given to group exercise sessions offered in nursing homes $(11,12)$. As we showed in a previous study, these sessions lead to additional physical activity (and thus higher energy expenditure) over a week (13). Moreover, physical activity programmes for older individuals appear to maintain physical activity levels and physical quality of life (14).

Some studies emphasize the importance of creating positive and pleasurable interactions and a supportive environment, which would encourage residents to participate in organized activities more regularly $(15,16)$. The motivation of the residents as well as the presence of a monitor seem to play a role in participation and adherence to soft gym sessions in nursing homes $(17,18)$. These observations converge in the motivational climate of the group exercise sessions proposed in nursing homes. It has been suggested that a motivational climate, defined as "a psychological environment guiding the goals and motivations of an individual" (19), has a favourable effect on physical performance, psychological state and commitment to exercise (20-24). However, enjoyment is also related to the motivational climate generated by the instructor and his or her communication style (22). Given the lack of information concerning this topic in nursing homes, we aimed to explore the motivational climate of group exercise sessions in nursing homes by interviewing participants using a validated questionnaire and to evaluate the association between the motivational climate and the characteristics of subjects.

\section{Methods}

\section{Design and sample}

This cross-sectional study included residents of ten nursing homes in the Liège area who attended group exercise sessions on a regular basis (i.e., at least 1 time per week) and were willing to collaborate on this research project. The research was conducted between July 2019 and September 2019. The subjects were included if they were aged 65 years or older, voluntarily participated in the study, had approved the informed consent form and were involved in the group gym session. The exclusion criteria were cognitive impairment (a mini mental state examination [MMSE] score $\leq 21$ out of 30 (25)) and a native language other than French. The study protocol was approved by the Ethics Committee of the University Teaching Hospital of Liège under number 2019/159.

\section{Subjects' characteristics}

Participants' sociodemographic and clinical data were collected from residents' medical records. The data considered were age, sex, body mass index (BMI), walking aid, independence in activities of daily living assessed by Katz's scale (26) and cognitive status evaluated by the MMSE (27)).

\section{Motivational climate}


The French version of the "Abbreviated Perceived Motivational Climate in Exercise Questionnaire (PMCEQ-A)" was administered face-to-face to each participant by a clinical researcher (28). Beforehand, the initial designers of the questionnaire, which had been developed in English, agreed to have the questionnaire translated into French. The questionnaire was translated by our division according to the guidelines of Beaton et al. (29). This questionnaire is used to assess the motivational context perceived by the subjects during group exercise sessions. It is composed of 12 items, including 6 items related to the task-involving climate and 6 items related to the ego-involving climate. The task-involving climate is focused in particular on the cooperation among participants, personal improvement or the valorisation of everyone. On the other hand, the ego-involving climate is characterized by the feeling of rivalry between the participants, the embarrassment of not knowing how to carry out the exercise or the feeling that only the best are valued. Each item is coded with a scale ranging from 1 (strongly disagree) to 5 (strongly agree). Each subscale has a total score expressed as an average (i.e., from 1 to 5). A higher score reflects a higher ego-involving climate or task-involving climate.

\section{Statistical methods}

The collected data were processed using SPSS software version 25 (IBM Corporation, Armonk, NY, USA). First, a descriptive analysis of the different variables was performed. The normality of these variables was tested using the Shapiro-Wilk test and QQ-plot. Normally distributed continuous quantitative variables were expressed as the mean and standard deviation (SD), while those with abnormal distributions were expressed as the median and percentiles (P25-P75). The qualitative variables were described in terms of number and frequency (\%). Then, the association between subjects' characteristics and motivational climate was evaluated with linear regressions (with adjustment on age and sex).

\section{Results}

\section{Study population}

Among 124 subjects meeting the inclusion criteria, a total of 102 subjects were included in this study (18 refused to participate). Table 1 presents the characteristics of the sample. The mean age of the participants was $84.3 \pm 7.7$ years, and $81.4 \%$ were female. The mean scores of task-involving and egoevolving motivational climate were $3.57(S D=0.67)$ and $1.52(S D=0.49)$, respectively.

\section{Motivational climate}

The response rates of 12 items of the A-PMCEQ are reported in Table 2. When looking separately at each ego-involving climate item, the results showed that $89.2 \%$ of respondents thought that residents were not hesitant to ask the instructor for help, $92.2 \%$ thought that they did not feel embarrassed if they did not know how to use the equipment or perform an exercise, $93.1 \%$ related that they are not encouraged to do better than others, $79.4 \%$ said that they are not excited when they do better than others, $92.2 \%$ said that the instructor paid attention to all of the participants and $97.1 \%$ said that the instructor does not make it clear who he/she thinks are the most fit. 
Regarding the items related to the task-involving climate, $93.1 \%$ of respondents found that residents of all fitness levels are made to feel valued, $76.5 \%$ of respondents said that the focus is to keep improving on each exercise/skill during each class session, $91.2 \%$ thought that the instructor emphasizes always trying one's best, $55.9 \%$ found that the instructor does not remark/reward when they try hard, $63.7 \%$ found that the instructor does not encourage participants to help each other and $38.2 \%$ found that the instructor does not encourage participants do new exercises.

\section{Motivational climate and characteristics}

Our secondary objective was to evaluate the association between participants' characteristics and perceived motivational climate. Our goal was to assess whether some characteristics (i.e., age, sex, BMI, cognitive status and Katz score) could have an influence on the perceived ego-involving or task-evolving climate. The results in Table 3 show that only independence was negatively associated with egoinvolving climate $(\beta=-0,049,95 \% \mathrm{Cl}=0,020-0,078, p=0,001)$. This means that residents with more dependency reported higher levels of ego-involving climate. There was no association between the other characteristics and motivational climate (ego-involving or task-evolving climate).

\section{Discussion}

This present research examined the motivational climate of group exercise sessions held in nursing homes. Our findings seem to suggest that the nursing home residents perceived their motivational climate as more task-oriented than ego-oriented. This trend is consistent with reports by other authors who have studied younger populations. Indeed, several studies recommended creating task-involving motivational climates in sport and physical education settings rather than ego-involving climates (3033). Interestingly, the task-involving climate has been positively related to the intrinsic motivation of individuals (i.e. interest, perception of competence, and effort-importance) (34). In contrast, the negative influence of the ego-involving climate on satisfaction and intrinsic motivation has been frequently noted $(35,36)$.

The detailed analysis of A-PMCEQ showed interesting results. Regarding ego-involving climate items, the majority of subjects (i.e., over $78 \%$ for each item) do not experience rivalry, favouritism or concerns about mistakes. Similarly, the caring climate usually established in nursing homes should negatively relate to perceptions of an ego-involving motivational climate (37). On the other hand, regarding task-oriented climate items, a large number of subjects experienced feelings of being valued, of individual improvement and of being encouraged to do their best. However, three item results were of particular interest. First, more than half of the respondents found that the instructor did not remark/reward when they tried hard. Nevertheless, previous studies have shown that positive feedback provided by instructors helped participants to gauge their personal progress and was an additional motivator (38-40). Moreover, rewarding the effort of participants is likely to generate satisfaction and pride (22). Second, almost twothirds of the subjects said that the instructor did not encourage them to help each other. One possible explanation is that the instructors do not encourage this behaviour because they want to guarantee the 
safety of participants. However, it has been reported that social interactions with other residentparticipants can serve as physical activity motivators (41). Third, one-third of participants found that the instructor did not encourage them to try new exercises. Nonetheless, other studies have confirmed that nursing home residents need variety and innovation in their exercise programmes (Maurer et al. 2018; Baert et al. 2015).

When we investigated the association between characteristics and motivational climate, we found a relationship between the perceived ego-involving motivational climate and the dependency of the participants. This means that those who were more dependent on help in their activities of daily living perceived a more ego-oriented motivational climate than those who were more independent in their activities of daily living. This would suggest that they felt they were being compared with others during group exercise sessions. There is some evidence to suggest that adapted exercises seemed to be essential for older people $(38,42)$. Therefore, several variants of the exercises could be proposed to the residents in order to elicit an optimal execution level in each resident, thus leading to a higher motivational level.

Regarding the practical implications of our results, it seems important to implement an adequate motivational climate during exercise sessions. In the literature, some recommendations for quality physical education interventions were established with, for example, the PAMIA principles (43). Pleasure, achievement, movement, interaction and autonomy are the 5 principles of these recommendations. Although they are not specific to older people, these can be related to the elements identified in our study

and are the key elements to prioritize when implementing group exercise sessions in nursing homes. The 3 elements highlighted in our study are related to the interaction among participants (for mutual aid), achievement (for diversified exercises and adapted exercise with a sufficient level of difficulty) and movement (for positive feedback) (43). These elements are also mentioned in the theory of selfdetermination as well as in the three psychological needs of Bandura (1977), namely, competence (adapted exercises and positive feedback), autonomy (diversified exercises and choices), and relatedness $(44,45)$.

It is important to recognize the possible bias and limitations of this study. The cross-sectional nature of this study allows us to generate descriptive results regarding motivational climate but no causal inferences between variables. The generalisability of these results is subject to certain limitation because our analysis was based on a relatively small sample. Additionally, the composition of the sample of oriented nursing home residents exclusively leads to a bias in the representativeness of the population. The results should be interpreted with caution because the A-PMCEQ was developed for the general population and not specifically for older people.

\section{Conclusion}

In conclusion, the A-PMCEQ is an interesting tool and highlighted a climate in nursing homes that is especially task-oriented. On the other hand, it does not add value to the ego-task distinction. Moreover, the 
lack of individual positive feedback, new exercises and mutual aid were emphasized. Special attention to adapted exercises should also be required. Future research is recommended to further investigate the quality of the intervention at the task level rather than the ego-task distinction.

\section{List Of Abbreviations}

IAGG: International Association of Gerontology and Geriatrics; WHO: World Health Organization; MMSE: mini mental state examination; BMI: body mass index; PMCEQ-A: Abbreviated Perceived Motivational Climate in Exercise Questionnaire; SD: standard deviation.

\section{Declarations}

\section{Ethics approval and consent to participate}

The study protocol was approved by the Ethics Committee of the University Teaching Hospital of Liège under number 2019/159.

\section{Consent for publication}

Not applicable

\section{Availability of data and materials}

The datasets used and analysed during the current study are available from the corresponding author on reasonable request.

\section{Competing interests}

The authors declare that they have no competing interests

\section{Funding}

There was no source of funding

\section{Authors' contributions}

Olivier Bruyère, Fanny Buckinx, Alexandre Mouton, Jean-Yves Reginster and Alexia Charles contributed to the conception and the design of the work. Alexia Charles have collected, analyzed and interpreted the patient data of the study. Alexia Charles have draft the work. All authors substantively revised it. All authors read and approved the final manuscript. All authors have agreed both to be personally accountable for the author's own contributions and to ensure that questions related to the accuracy or integrity of any part of the work, even ones in which the author was not personally involved, are appropriately investigated, resolved, and the resolution documented in the literature. 
Acknowledgements

Not applicable

\section{References}

1. De Carvalho Bastone A, Jacob Filho W. Effect of an exercise program on functional performance of institutionalized elderly. J Rehabil Res Dev. 2004;41(5):659-68.

2. Hrubeniuk TJ, Sénéchal M, Mayo A, Bouchard DR. Association between physical function and various patterns of physical activity in older adults: a cross-sectional analysis. Aging Clin Exp Res. 2019;

3. Venturelli M, Lanza M, Muti E, Schena F. Positive effects of physical training in activity of daily livingdependent older adults. Exp Aging Res. 2010;36(2):190-205.

4. Zhao M, Gao J, Li M, Wang K. Relationship Between Loneliness and Frailty Among Older Adults in Nursing Homes: The Mediating Role of Activity Engagement. J Am Med Dir Assoc. 2019;20(6):75964.

5. Scarabottolo CC, Cyrino ES, Nakamura PM, Tebar WR, Canhin S, Gobbo LA, et al. Relationship of different domains of physical activity practice with health- related quality of life among communitydwelling older people: a cross-sectional study. BMJ. 2019;9(3):1-10.

6. Clemson L, Ot B, Ot M, Cumming ÃRG, Kendig H, Swann M, et al. The Effectiveness of a CommunityBased Program for Reducing the Incidence of Falls in the Elderly: A Randomized Trial. JAGS. 2004;52(9):1487-94.

7. Landi F, Cesari M, Onder G, Lattanzio F, Gravina EM. Physical Activity and Mortality in Frail , Community-Living Elderly Patients. J Gerontol. 2004;59(8):833-7.

8. Brown JC, Harhay MO, Harhay MN. Physical activity, diet quality, and mortality among sarcopenic older adults. Aging Clin Exp Res. 2017;29(2):257-63.

9. Tolson D, Rolland Y, Andrieu S, Aquino JP, Beard J, Benetos A, et al. International Association of Gerontology and Geriatrics: A Global Agenda for Clinical Research and Quality of Care in Nursing Homes. J Am Med Dir Assoc. 2011;12(3):184-9.

10. Buckinx F, Mouton A, Reginster JY, Croisier JL, Dardenne N, Beaudart C, et al. Relationship between ambulatory physical activity assessed by activity trackers and physical frailty among nursing home residents. Gait Posture. 2017;54:56-61.

11. Finnegan S, Bruce J, Lamb SE, Griffiths F. Predictors of attendance to group exercise: A cohort study of older adults in long-term care facilities. BMC Geriatr. 2015;15(1):1-12.

12. Chetty L, Ramklass SS, McKune AJ. The effects of a structured group exercise programme on functional fitness of older persons living in old-age homes. Ageing Soc. 2019;39(9):1857-72.

13. Charles A, Buckinx F, Mouton A, Reginster JY, Petermans J, Gruslin B, et al. Energy Expenditure of Nursing Home Residents and Participation in Exercise Classes: An Analysis of the SENIOR Cohort. $J$ 
Am Med Dir Assoc. 2019;20(9):1183-4.

14. Lindsay-Smith G, Eime R, O'Sullivan G, Harvey J, Van Uffelen JGZ. A mixed-methods case study exploring the impact of participation in community activity groups for older adults on physical activity, health and wellbeing. BMC Geriatr. 2019;19(1):1-15.

15. Chen Y-M. Perceived barriers to physical activity among older adults residing in long-term care institutions. J Clin Nurs. 2010;19:432-9.

16. Chen YM, Li YP. Motivators for physical activity among ambulatory nursing home older residents. Sci World J. 2014;

17. De Souto Barreto P, Demougeot L, Vellas B, Rolland Y. How much exercise are older adults living in nursing homes doing in daily life? A cross-sectional study. J Sports Sci [Internet]. 2015;33(2):11624. Available from: http://dx.doi.org/10.1080/02640414.2014.928828

18. Altintas E, Guerrien A, Vivicorsi B, Clément E, Robert J, Altintas E, et al. Leisure Activities and Motivational Profiles in Adaptation to Nursing Homes. Can J Aging. 2018;1-12.

19. Ames C. Achievement Goals, Motivational Climate, and Motivational Processes. Roberts. IL: Human Kinetics; 1992. 161-176 p.

20. Brown TC, Fry MD. College exercise class climates, physical self-concept, and psychological wellbeing. J Clin Sport Psychol. 2014;8(3):299-313.

21. Brown TC, Fry MD. Motivational climate, staff and members' behaviors, and members' psychological well-being at a national fitness franchise. Res Q Exerc Sport. 2014;85(2):208-17.

22. Alesi M, Gómez-López M, Borrego CC, Monteiro D, Granero-Gallegos A. Effects of a motivational climate on psychological needs satisfaction, motivation and commitment in teen handball players. Int J Environ Res Public Health. 2019;16(15):1-13.

23. Smith RE, Smoll FL, Cumming SP. Effects of a Motivational Climate Intervention for Coaches on Young Athletes ' Sport Performance Anxiety. J Sport Exerc Psychol. 2007;29:39-59.

24. Morgan K. Reconceptualizing Motivational Climate in Physical Education and Sport Coaching: An Interdisciplinary Perspective Reconceptualizing Motivational Climate in Physical Education and Sport Coaching: An Interdisciplinary Perspective. Quest. 2016;

25. Folstein MF, Folstein SE, McHugh PR. Mini-mental state. J Psychiatr Res. 1975;12(3):189-98.

26. Katz S, Ford AB, Moskowitz RW, Jackson BA, Jaffe MW. Studies of Illness in the Aged The index of ADL : A Standardized Measure of Biological and Psychosocial Function. JAMA. 1963;95(12):914.

27. Tombaugh TN, Mclntyre NJ. The Mini-Mental State Examination: A Comprehensive Review. J Am Geriatr Soc. 1992;40:922-35.

28. Moore EWG, Brown TC, Fry MD. Psychometric Properties of the Abbreviated Perceived Motivational Climate in Exercise Questionnaire. Meas Phys Educ Exerc Sci. 2015;19(4):186-99.

29. Beaten DT, Bombardier C, Guillemin F, MB F. Guidelines for the process of Cross Cultural adaptation of Self Report mesures. Spine (Phila Pa 1976). 2000;25(24):3186-91. 
30. Cuberos RC, Ortega FZ, Molero PP, Knox E. Relationship between Healthy Habits and Perceived Motivational Climate in Sport among University Students: A Structural Equation Model. Sustainability. 2018;10(938).

31. Cox A. The Roles of Perceived Teacher Support, Motivational Climate, and Psychological Need Satisfaction in Students ' Physical Education Motivation. J Sport Exerc Psychol. 2008;30:222-39.

32. Parish LE, Treasure DC. Physical activity and situational motivation in physical education: influence of the motivational climate and perceived ability. Res Q Exerc Sport. 2003;74(2):173-82.

33. Buzzelli AA, Draper JA. Examining the Motivation and Perceived Benefits of Pickleball Participation in Older Adults. J Aging Phys Act. 2019;1-7.

34. Escartí A, Gutiérrez M. Influence of the motivational climate in physical education on the intention to practice physical activity or sport. Eur J Sport Sci. 2001;1(4):1-12.

35. Standage M, Duda JL, Ntoumanis N. A model of contextual motivation in physical education: Using constructs from self-determination and achievement goal theories to predict physical A Model of Contextual Motivation in Physical Education: Using Constructs From Self-Determination and Achie. J Educ Psychol. 2003;95(1):97-110.

36. González-cutre D, Sicilia Á. Motivation and Exercise Dependence: A Study Based. Res Quaterly Exerc Sport. 2013;83(2):318-29.

37. Newton M, Fry MD, Watson DL, Gano-Overway L a, Kim MS, Magyar MT, et al. Psychometric properties of the caring climate scale in a physical activity setting. Rev Psicol del Deport. 2007;16(1):67-84.

38. Farrance C, Tsofliou F, Clark C. Adherence to community based group exercise interventions for older people: A mixed-methods systematic review. Prev Med (Baltim). 2016;87:155-66.

39. İlker GE, Aşçi H. The Role of Teacher's Feedback in Physical Education: Motivational Climate as Mediator. J Educ. 2019;34(2):372-86.

40. Hawley-Hague H, Horne M, Campbell M, Demack S, Skelton DA, Todd C. Multiple levels of influence on older adults' attendance and adherence to community exercise classes. Gerontologist. 2014;54(4):599-610.

41. Baert V, Gorus E, Guldemont N, De Coster S, Bautmans I. Physiotherapists' perceived motivators and barriers for organizing physical activity for older long-term care facility residents. J Am Med Dir Assoc. 2015;16(5):371-9.

42. Phillips EM, Schneider JC, Mercer GR, Em AP, Jc S, Moti- MGR. Motivating Elders to Initiate and Maintain Exercise. Arch Phys Med Rehabil. 2004;85:52-7.

43. Cloes M. Preparing physically educated citizens in physical education. Expectations and practices. Retos. 2017;31:245-51.

44. Ryan RM, Deci E. Overview of self-determination theory: An organismic-dialectical perspective. University. Rochester, NY; 2002.

45. Bandura A. Social learning theory. Prentice H. Englewood Cliffs, NJ; 1977. 


\section{Tables}

Table 1. Characteristics of study population $(\mathrm{N}=102)$

\begin{tabular}{ll}
\hline Variables & Mean \pm SD or Median (P25-P75) or N (\%) \\
\hline Age (years) & $84.3 \pm 7.7$ \\
Sex (women) & $83(81.4)$ \\
\hline BMI $\left(\mathrm{kg} / \mathrm{m}^{2}\right)$ & $26.3 \pm 5.4$ \\
\hline Walking aid & \\
\hline No & $27(26.5)$ \\
\hline yes & $75(73.5)$ \\
\hline MMSE score (/30) & $25.3 \pm 3.3$ \\
\hline Katz score (/32) & $11(9-13)$ \\
\hline Motivational climate & \\
\hline Ego-involving (1-5) & $1.5 \pm 0.5$ \\
\hline Task-involving (1-5) & $3.6 \pm 0.7$ \\
\hline
\end{tabular}

SD Standard deviation; N Number

Table 2. Results for ego-involving and task-involving climate items in Abbreviated Perceived Motivational Climate in Sport Questionnaire ( $\mathrm{N}=102)$ 


\begin{tabular}{|c|c|c|c|c|c|c|}
\hline & Items & $\begin{array}{l}\text { Completely } \\
\text { agree } \\
\mathrm{N}(\%)\end{array}$ & $\begin{array}{l}\text { Partly } \\
\text { agree } \\
\text { N (\%) }\end{array}$ & $\begin{array}{l}\text { Neutral } \\
\text { N(\%) }\end{array}$ & $\begin{array}{l}\text { Partly } \\
\text { disagree } \\
\mathrm{N}(\%)\end{array}$ & $\begin{array}{l}\text { Completely } \\
\text { disagree } \\
\mathrm{N}(\%) \\
\end{array}$ \\
\hline \multirow[t]{7}{*}{$\begin{array}{c}\text { Ego- } \\
\text { involving }\end{array}$} & $\begin{array}{l}\text { Members are } \\
\text { hesitant/embarrassed to } \\
\text { ask the instructor/staff } \\
\text { for help }\end{array}$ & $2(2.0)$ & $\begin{array}{l}8 \\
(7.8)\end{array}$ & $1(1.0)$ & $\begin{array}{l}21 \\
(20.6)\end{array}$ & $70(68.6)$ \\
\hline & $\begin{array}{l}\text { The instructor/ staff gives } \\
\text { most of his/her attention } \\
\text { to only a few members } \\
\text { (high status, most fit, } \\
\text { etc.) }\end{array}$ & $1(1.0)$ & $\begin{array}{l}7 \\
(6.9)\end{array}$ & $0(0)$ & $\begin{array}{l}13 \\
(12.7)\end{array}$ & 81 (79.4) \\
\hline & $\begin{array}{l}\text { Members feel } \\
\text { embarrassed if they do } \\
\text { not know how to use the } \\
\text { equipment or perform the } \\
\text { exercise/skill/drill }\end{array}$ & $0(0)$ & $\begin{array}{l}9 \\
(8.8)\end{array}$ & $0(0)$ & $\begin{array}{l}26 \\
(25.5)\end{array}$ & 67 (65.7) \\
\hline & $\begin{array}{l}\text { Members are encouraged } \\
\text { to do better than other } \\
\text { members }\end{array}$ & $5(4.9)$ & $0(0)$ & $2(2.0)$ & $\begin{array}{l}28 \\
(27.5)\end{array}$ & 67 (65.7) \\
\hline & $\begin{array}{l}\text { The instructor/staff } \\
\text { makes it clear who he/she }\end{array}$ & $0(0)$ & $\begin{array}{l}3 \\
(3.0)\end{array}$ & $0(0)$ & $\begin{array}{l}17 \\
(16.7)\end{array}$ & $82(80.4)$ \\
\hline & & & & & & \\
\hline & $\begin{array}{l}\text { Members are excited } \\
\text { when they do better than } \\
\text { their fellow classmates }\end{array}$ & $1(1.0)$ & $\begin{array}{l}20 \\
(19.6)\end{array}$ & $0(0)$ & $\begin{array}{l}23 \\
(22.5)\end{array}$ & $58(56.9)$ \\
\hline \multirow[t]{6}{*}{$\begin{array}{c}\text { Task- } \\
\text { involving }\end{array}$} & $\begin{array}{l}\text { The instructor/staff } \\
\text { encourages us to try new } \\
\text { exercises/skills }\end{array}$ & $33(32.4)$ & $\begin{array}{l}28 \\
(27.5)\end{array}$ & $1(1.0)$ & $\begin{array}{l}25 \\
(24.5)\end{array}$ & $14(13.7)$ \\
\hline & $\begin{array}{l}\text { Members of all fitness } \\
\text { levels are made to feel } \\
\text { valued }\end{array}$ & $49(48.0)$ & $\begin{array}{l}46 \\
(45.1)\end{array}$ & $1(1.0)$ & $4(3.9)$ & $2(2.0)$ \\
\hline & $\begin{array}{l}\text { Members are rewarded } \\
\text { and noticed when they try } \\
\text { hard }\end{array}$ & 20 (19.6) & $\begin{array}{l}22 \\
(21.6)\end{array}$ & $3(3.0)$ & $\begin{array}{l}34 \\
(33.3)\end{array}$ & $23(22.5)$ \\
\hline & $\begin{array}{l}\text { The instructor/staff } \\
\text { encourages members to } \\
\text { help each other }\end{array}$ & $12(11.8)$ & $\begin{array}{l}24 \\
(23.5)\end{array}$ & $1(1.0)$ & $\begin{array}{l}17 \\
(16.7)\end{array}$ & $48(47.1)$ \\
\hline & $\begin{array}{l}\text { The instructor/staff } \\
\text { emphasizes always trying } \\
\text { your best }\end{array}$ & $67(65.7)$ & $\begin{array}{l}26 \\
(25.5)\end{array}$ & $0(0)$ & $6(5.9)$ & $3(2.9)$ \\
\hline & $\begin{array}{l}\text { The focus is to keep } \\
\text { improving on each } \\
\text { exercise/skill each class } \\
\text { session }\end{array}$ & 43 (42.) & $\begin{array}{l}35 \\
(34.3)\end{array}$ & $0(0)$ & $\begin{array}{l}22 \\
(21.6)\end{array}$ & $2(2.0)$ \\
\hline
\end{tabular}

N Number

Table 3. Association between characteristics and ego-evolving climate/ task-evolving climate $(\mathrm{N}=102)$ 


\begin{tabular}{|c|c|c|c|c|c|c|c|c|c|c|}
\hline & \multicolumn{5}{|c|}{ Ego-involving climate } & \multicolumn{5}{|c|}{ Task-involving climate } \\
\hline Variables & Estimate & $\begin{array}{l}\text { Standard } \\
\text { Error (SE) }\end{array}$ & $95 \% \mathrm{CI}$ & & $\begin{array}{l}\mathrm{p} \\
\text { value }\end{array}$ & Estimat & $\begin{array}{l}\text { Standard } \\
\text { Error (SE) }\end{array}$ & $95 \% \mathrm{CI}$ & & $\begin{array}{l}\text { p } \\
\text { value }\end{array}$ \\
\hline Age & -0.003 & 0.006 & -0.016 & 0.009 & 0.613 & -0.009 & 0.009 & -0.027 & 0.008 & 0.293 \\
\hline $\begin{array}{l}\text { Sex } \\
\text { (women) }\end{array}$ & -0.170 & 0.123 & -0.413 & 0.074 & 0.170 & -0.018 & 0.172 & -0.360 & 0.323 & 0.916 \\
\hline BMI & -0.012 & 0,010 & -0.032 & 0.007 & 0.218 & 0.013 & 0.014 & -0.014 & 0.041 & 0.337 \\
\hline $\begin{array}{l}\text { Katz } \\
\text { score }\end{array}$ & 0.049 & 0,015 & 0.020 & 0.078 & 0.001 & -0.005 & 0.020 & -0.045 & 0.034 & 0.789 \\
\hline $\begin{array}{l}\text { MMSE } \\
\text { score }\end{array}$ & -0.008 & 0.015 & -0.038 & 0.022 & 0.592 & -0.007 & 0.021 & -0.049 & 0.035 & 0.744 \\
\hline
\end{tabular}

SE Standard error; Cl Confidence interval; BMI Body mass index 